\title{
Psychological Capital and Core Self-Evaluations in the Workplace: Impacts on Well-Being
}

\author{
Annita Gibson ${ }^{1} \&$ Richard E. Hicks ${ }^{1}$ \\ ${ }^{1}$ School of Psychology, Bond University, Robina, Queensland, Australia \\ Correspondence: Richard E. Hicks, School of Psychology, Bond University, Robina, Queensland-4229, Australia
}

Received: February 16, 2018

Accepted: March 9, 2018

Online Published: April 2, 2018

doi:10.5539/ijps.v10n2p15

URL: https://doi.org/10.5539/ijps.v10n2p15

\begin{abstract}
The uncertainty of today's working environment, including prevalence of temporary employment conditions in many industries, has affected the psychological well-being of people in the workforce. Psychological well-being affects all aspects of a person's life, including: pleasure, job satisfaction and fulfilment, and life meaning (Seligman, 2002). Previous studies have investigated how Psychological Capital (PsyCap) and Core Self-evaluations (CSE) are positively related to job satisfaction and performance, but there is little research on the relationships of PsyCap and CSE with psychological well-being (PWB). This present study explored the relationships among PsyCap, CSE, and PWB in a convenience workplace sample of 121 Australian working adults. Results revealed that both PsyCap (involving hope, optimism, resilience and self-efficacy) and CSE (involving evaluations of one's own locus of control, self-esteem, generalised self-efficacy, and adaptive vs 'neurotic' behaviour) were separately positive predictors of wellbeing, consistent with previous studies. There were overlaps in concepts but both PsyCap and CSE together predicted higher levels of well-being than either alone, and CSE was found to be a partial mediator between PsyCap and well-being indicating that both elements were needed in prediction of well-being. Practical implications include that PsyCap and CSE measures can be used together in the workplace in assessment, selection, training and development to help improve the quality of health and well-being of employees. Limitations and future research directions are indicated.
\end{abstract}

Keywords: well-being, psychological capital, core self-evaluations

\section{Introduction}

Despite extensive recent research investigating the relationship between Psychological Capital (PsyCap) and job satisfaction and performance (e.g., Avey, Luthans, Smith, \& Palmer, 2010), presently just a few studies (e.g., Culbertson, Fullagar, \& Mills, 2010) have explored the relationship between PsyCap and traits associated with well-being. The current study investigated the personal PsyCap state-like resources and personal Core Self-Evaluations (CSE) trait-like resources, and their relationships with well-being. As a consequence of advances in technology and globalisation, business and professional workplaces have become increasingly demanding and high levels of well-being in staff are needed to contribute to successful performance (Rath \& Harter, 2010).

In recent decades there has been a reduction in permanent employment conditions, and a rise in short-term contracts, and temporary, casual and part-time employment (Mitchell \& Kristovics, 2005; Sparks et al., 2001), including during and after the global financial crisis of 2008-2009 (as noted, for example, in Tora, Martinez, Benavides, Leveque, \& Ronda, 2015). This indicates the examination of well-being in the workplace may be needed, including into employee ability to handle longerterm insecurity and change. The effects of job insecurity have been found to impact people's physical and psychological health, as well as to increase negative emotions including, anxiety, depression, hostility, and feelings of despair. Moreover, an unstable workplace creates employee distrust in the organisation (Culbertson et al., 2010; Diener \& Seligman, 2004). Well-being is therefore significant in contributing to organisational outcomes. We examine psychological well-being in more detail next, with special attention to Ryff's model of well-being and the associated scale commonly used to measure well-being and then examine psychological qualities and core self evaluations of individuals as we seek to understand how individuals cope and how they may be helped to cope better.

\subsection{Psychological Well-being at Work}

Ryff's (1995) model of wellbeing identified six distinct dimensions as significant contributors to psychological 
well-being: Self-Acceptance, Environmental Mastery, Purpose in Life, Positive Relations with Others, Personal Growth, and Autonomy, as described also more recently by Ryff and Singer (2013) and in relation to the workplace, by Žižek, Treven, and Čančer (2015). Žižek et al. (2015) indicated that employees with higher levels of PWB experience greater personal freedom, a purposeful life, and goal directed skills development, and tend to be enthusiastic, show greater organisational commitment, and be happier in their personal life (than those with lower levels of well-being). Stajkovic (2006) suggested that engagement in stimulating work and demonstrating "confidence" (PsyCap) are contributing factors to successful work performance. When work tasks are challenging yet achievable, employees tend to perform better, experience greater levels of satisfaction, and have increased self-efficacy, self-esteem and optimism as a result. These aspects are related both to psychological capital attributes and to 'core' self-evaluations. We will discuss these attributes (PsyCap and CSE) in more detail subsequently. However, first we present a theoretical background to our interest in PsyCap and Core Self-Evaluations at the workplace.

\subsection{Background Theories Related to PsyCap, Core Self-Evaluation and Psychological Well-being}

PsyCap draws from several theories including Social Cognitive Theory (Bandura,1997), establishing reciprocal interactions among the person, the environment, and past behaviour. Empirical evidence suggests that the determinants of social cognitions are mechanisms for motivation and regulating behaviour. But other theories also support research using PsyCap and Core Self-Evaluation attributes. For example, Goal-Setting Theory (Locke \& Latham, 2006) suggests: 1) That the more difficult the goal, the higher the level of effort and performance the person produces; and 2) That specific, difficult goals lead to greater performance than simply being told to 'do your best'. Goal setting that follows the SMART model (specific, measurable, attainable, realistic and time-framed) produces reliable outcomes, basic to Psychological Capital Interventions (Russo \& Stoykova, 2015). Theoretical impacts of wellbeing include, as suggested by Rath and Hartner (2010), impacts on: Careers; Social relationships; Financial return and overall standard of living; Physical health; and ability to contribute to Community. Wellbeing has also been associated with mental health, longevity, and supportive social connectedness (Diener \& Seligman, 2004). Details follow as to how PsyCap and Core Self-Evaluations may contribute to wellbeing.

\subsection{Psychological Capital}

Psychological Capital (PsyCap) refers to individuals' positive psychological states of development (Luthans \& Youssef-Morgan, 2017) and the psychological resources (such as resilience, self-efficacy, hope and optimism) to draw upon when efforts are failing or have failed (Karatepe \& Karadas, 2015). Despite the similarities between the constructs of hope, resilience, optimism, and efficacy that make up PsyCap, each has been analysed and demonstrate construct validity (Avey, Luthans, \& Youssef, 2010). Positive PsyCap supports hardiness, and the ability to change direction and re-set goals where needed (Luthans, Avolio, Avey, \& Norman, 2007; Luthans et al., 2004). Furthermore, such resources provide a psychological advantage in any given environment; to think and foster behaviour development for greater results (Luthans \& Avolio, 2014; Yang \& Cho, 2015). PsyCap has been positively related to performance and wellbeing in the workplace, more so than any one of the single sub-dimension alone of self-efficacy, optimism, hope, and resilience (Avey et al., 2010; Luthans \& Youssef, 2007; Luthans \& Youssef-Morgan, 2017; Stajkovic, 2006). The subscales making up PsyCap are discussed next.

Self-efficacy is defined as a belief regarding one's capabilities to execute a specific task within a given, specific context (Bandura, 1997). For example, satisfied employees in a resourceful work environment (in the hotel industry) have been found to be self-efficacious and goal- and task-oriented (Karatepe \& Karadas, 2015).

Resilience is the capacity to respond to pressures quickly, adaptively, and effectively. It is valued in the workplace, as it refers to an employees' ability to be flexible and improvise when challenges arise, to use judgment, discretion, control, and decision latitude, and to develop further through training, skills, knowledge, and an ability to respond successfully to challenging situations (Coutu, 2002; Graham, 2013; Sutcliffe \& Vogus, 2003).

Optimism is associated with cognitive processing of expectations and with making positive attributions about succeeding now and in the future (Luthans \& Youssef, 2007). A study of insurance salesman found the top half of optimistic sales agents sold $37 \%$ more insurance than the bottom half and had higher retention rates, were more satisfied, and had less stress than their more pessimistic counterparts (Schulman, 1999).

Hope is an expectation of a positive outcome and a set of cognitions based on successful: (a) agency (goal-directed determination) and (b) pathways thinking (planning of ways to meet goals) (Snyder et al., 1991). To date there has been a little but not extensive research on hope in work contexts (e.g., Stajkovic, 2006). Individuals who possess hope, are flexible and capable of re-setting goals when necessary. Hope in stressful jobs is negatively related to emotional exhaustion and turnover and positively related to performance (Avey, Luthans, \& Jensen, 2009). 
This study in part, replicates previous studies that have investigated PsyCap and the relationship to performance and satisfaction at work; however, we are interested in the relationships between PsyCap and Core Self-Evaluations, and psychological wellbeing and thus we explore CSE next.

\subsection{Core Self-Evaluation (CSE)}

CSE is a broad, higher-order construct of personality that is fundamentally trait-like and is comprised of four narrow traits well established in personality literature (e.g., Judge, Bono, Erez, \& Locke, 2005). These four are: a) Self-Esteem, which refers to the value people place on themselves (Harter, 1990); b) generalised Self-Efficacy, which relates to the evaluation of one's ability to perform across various situations (Locke, McClear, \& Knight, 1996); c) Neuroticism (reverse marked) which describes the tendency to have negative thoughts and appraisals of oneself over a variety of situations (Watson, 2001); and d) Locus of Control, which refers to individuals' beliefs about the control they have over events that occur in their life (Rotter, 1966). Individuals who score high on total CSE tend to be well adjusted, positive, self-confident and effective, which then manifests in higher levels of self-esteem, emotional stability, general self-efficacy, and stronger internal locus of control (Judge, Erez, Bono, $\&$ Thoressen, 2003). Self-esteem is often used somewhat interchangeably with self-efficacy; however, they represent different phenomena. Perceived self-efficacy is concerned with judgements of personal capability, whereas self-esteem is concerned with judgements of self-worth. People need more than self-esteem to do well in given pursuits (Bandura, 1997). Generalised self-efficacy is seen as a trait-based version of self-efficacy (Sherer et al., 1982). Self-efficacy beliefs are based on four principal sources of information: 1) enactive mastery experiences that serve as indicators of capability; 2) vicarious experiences that alter efficacy beliefs through transmission of competencies and comparison with the attainments of others; 3) verbal persuasion and allied types of social influences that one possesses certain capabilities; 4) physiological and affective states from which people judge themselves in terms of capability, their strength, and their vulnerability to dysfunction (Bandura, 1997). CSE extends upon the five-factor model of personality (McCrae \& Costa, 1987) and has been found to be stable and reliable (Judge \& Bono, 2001), to predict job and life satisfaction and job performance (cf., Judge \& Hurst, 2007; Tsaousis, Nikolaou, Serdaris, \& Judge, 2007).

\subsection{Background rationale to Current Study}

By understanding and recognising the need to support the wellbeing of employees, organisations can place greater emphasis on intervention programs that strengthen PsyCap and increase positive personality traits in the workplace (Russo \& Stoykova, 2015). It is beneficial for the organisation, because employees with elevated wellbeing tend to take fewer sick-leave days, are more productive, and have greater organisational commitment (Rath \& Harter, 2010). Research now suggests that despite personality traits generally being stable, there is still flexibility for change in those personality traits. For example, it is possible to decrease levels of neuroticism a person experiences when overall CSE (and PsyCap) are strengthened. Extending upon previous research, the aim of the current study was to examine the relationships among PsyCap, CSE and psychological wellbeing. Regression analysis aimed to determine whether trait-like (CSE) or state-like (PsyCap) factors were most associated with wellbeing outcomes (Luthans, Avolio, Avey, \& Norman, 2007). Investigating the relationship between state-like PsyCap and the mediating effect of CSE that contribute to wellbeing may shed some light on this question.

\subsection{Hypotheses}

The first two hypotheses aimed to add to previous studies that show PsyCap and CSE were positively related to job performance and job satisfaction (Judge \& Bono, 2001; Luthans et al., 2007), by examining similar relationships with psychological wellbeing rather than performance and satisfaction. The third hypothesis considered whether both elements contributed significantly together to psychological wellbeing. The fourth hypothesis examined whether, as in studies showing that personality mediates between PsyCap and job performance and satisfaction (Luthans et al., 2007), CSE (as a more personality-oriented set of qualities) would mediate betweenn PsyCap and Wellbeing.

The specific hypotheses follow:

$\mathrm{H}_{1}$ : PsyCap would have a positive relationship with wellbeing

$\mathrm{H}_{2}$ : CSE would have a positive relationship to wellbeing

$\mathrm{H}_{3}$ : PsyCap and CSE would both have positive relationships to wellbeing and together add increased value to predicting psychological wellbeing (multiple hierarchical regression)

$\mathrm{H}_{4}$ : CSE would be a mediator of the PsyCap - Wellbeing relationship. 


\section{Method}

\subsection{Participants}

A convenience sample of 121 employed participants (47 males - 38.8\%; 74 females $-61.2 \%$ ), aged 18 to 74 years $(M=43$ years; $S D=11.6 y r s)$ completed an online demographics questionnaire and several scales. Members came from a variety of employment backgrounds (e.g. Casino \& Hotel Industry, Tourism, Hospitality, Education, Medicine, Mental Health, Marketing, Sales, Real Estate, Arts and Theatre, and Self-employed). Relationships status indicated: 40 single, 49 married, 19 de-facto, and 13 divorced individuals. Level of education attained showed 39 achieving high school, and 82 achieving post high school qualifications.

\subsection{Materials}

Ryff's Psychological Wellbeing Scale. The Ryff's Psychological Wellbeing Scale, 42-item version (PWB; Ryff, 1995) was used to measure six dimensions of psychological wellbeing (i.e., self-acceptance, positive relations with others, autonomy, environmental mastery, purpose in life, and personal growth). The original scale was a 6-point Likert scale. The addition of "Neither agree nor disagree" to give a seven-point scale, was included in the current study. This was to create uniformity of response options with other scales in the survey. In our study the Cronbach alpha for total scale was 0.93 . The sub-scales' internal reliability coefficients can be seen in Table 1 and are similar to those reported in other studies (e.g., Kállay, 2013; Ryff, 1989).

Psychological Capital Questionnaire. The Psychological Capital Questionnaire (PCQ; Luthans, Avolio, Avey, \& Norman, 2007) is a 24-item scale with four sub-dimensions: self-efficacy, hope, resilience and optimism. PsyCap is the composite (higher-order) factor of the four facets. Response options in the original scale range from 1 (Strongly disagree) to 6 (Strongly agree). For this study, the scale was extended to a 7-point Likert scale to include a middle response option, "Neither agree nor disagree". The Cronbach alpha for the overall scale was $\alpha=.90$. See Table 1 for the sub-scales reliability coefficients. In previous studies; Self-efficacy $\alpha=.80$; Hope $\alpha=.76$; Resilience $\alpha=.70$; and Optimism $\alpha=.75$. Overall scale $\alpha=.89$ (Luthans et al., 2007). The Cronbach Alpha internal consistency coefficients for the current study for the total PCQ and its four subscales are shown in Table 1.

Core Self-Evaluations Scale (CSES; Judge, Bono, Erez, \& Locke, 2005). The Core Self-Evaluations Scale (CSES) contains 12-items measuring four specific core traits (self-esteem, generalized self-efficacy, neuroticism, and locus of control). The CSES was found to have sound psychometrics and correlated significantly with job satisfaction, job performance, and life satisfaction (e.g., Chang, Ferris, Johnson, Rosen, \& Tan, 2012; Dorman, Fay, Zapf, \& Frese, 2006; Judge \& Bono, 2001). An overall Cronbach's Alpha coefficient of 0.85 was found; and sub-scale coefficients with relevant external scales ranged from 0.64 to 0.87 (e.g., with Neuroticism in McCrae \& Costa's (1987) NEO-PI scale; with Rosenberg's (1965) Self-Esteem 10-item scale; with Judge et al.'s (1998) Generalised Self-Efficacy scale; and and Levenson's (1981) Internal, Powerful Others, and Chance (IPC) Scale (for Locus of Control) (Judge et al., 2003). The Cronbach Alpha internal consistency coefficients for the current study for the total CSE and its four subscales are shown in Table 1.

Table 1. Means, standard deviations, and Cronbach alpha coefficients of psychological capital, core self-evaluations, and their sub-scales, and correlation coefficients of these variables with psychological wellbeing

\begin{tabular}{lllll}
\hline & \multicolumn{2}{c}{$M(S D)$} & $\begin{array}{l}\text { Cronbach } \\
\text { Alpha }\end{array}$ & $\begin{array}{l}\text { Correlations of variables } \\
\text { with PWB }\end{array}$ \\
\hline Psychological Wellbeing & 221.15 & $(27.41)$ & .93 & - \\
Psychological Capital & 127.33 & $(15.37)$ & .90 & $.66^{* * *}$ \\
Self-efficacy & 31.42 & $(5.74)$ & .83 & $.53^{* * *}$ \\
Hope & 31.45 & $(4.97)$ & .80 & $.52^{* * *}$ \\
Resilience & 33.43 & $(4.09)$ & .70 & $.45^{* * *}$ \\
Optimism & 31.02 & $(4.67)$ & .79 & $.58^{* * *}$ \\
Core Self-evaluations & 61.10 & $(9.58)$ & .85 & $.75^{* * *}$ \\
Neuroticism & 14.12 & $(3.21)$ & .54 & $-.63^{* * *}$ \\
Generalised Self-efficacy & 17.02 & $(2.01)$ & .67 & $.69^{* * *}$ \\
Self-esteem & 15.04 & $(3.50)$ & .71 & $.61^{* * *}$ \\
Locus of control & 14.88 & $(2.80)$ & .47 & $.59^{* * *}$ \\
\hline
\end{tabular}

Note. $N=121 . * \mathrm{p}<.05 ; * * \mathrm{p}<.01 ; * * * \mathrm{p}<.001$. 


\subsection{Design and Procedure}

The present study used a non-experimental, correlational design. Hierarchical multiple regressions were used to determine the influence of core self-evaluations (trait-like factors) and psychological capital (state-like factors) on the criterion variable, wellbeing. Following University ethics approval, data was collected over three months via social media platforms, survey flyers on workplace noticeboards with anonymous link to survey attached, and via email invitation, using online Qualtrics (@2016 QUALTRICS, LLC).

\section{Results}

\subsection{Preliminary Analyses}

Data cleaning and screening for assumptions occurred; leading to 15 cases being removed. A trend for incomplete responses occurred towards the end of the overall questionnaire. The final sample size was $N=121$. Multicollinearity was not an issue and assumptions were met. An independent-samples t-test showed no significant difference between the male and female groups. As shown in Table 1 above, PsyCap correlated 0.51 with CSE and the correlations between each of the sub-variables ranged from 0.45 to 0.69 . The total PCQ scale correlated strongly with wellbeing (.66). The PsyCap subscales showed strong correlations also with PWB wellbeing (0.45 to 0.58). Similarly for the CSE scale, the CSE total correlated 0.75 with PWB, with the subscales of CSE correlating from 0.59 to 0.69 with PWB (neuroticism, negatively at -0.61).

\subsection{Main Analyses}

Standard multiple regressions were run to test the hypotheses. Independent variables were total PsyCap and total CSE, with the dependent variable being total wellbeing. Alpha of .05 was used. Each of the scales (total PsyCap and total CSE) correlated moderately with total wellbeing (.66 and .75 respectively).

Hypothesis 1, that PsyCap would be positively correlated with wellbeing, was supported (Table 2). R was significant, $F(1,119)=92.56, p<.001$, with $\mathrm{R}^{2}$ at .44 . The adjusted $\mathrm{R}^{2}$ value of .43 when using total PsyCap only, indicated that $43 \%$ of the variance of wellbeing was accounted for by total PsyCap. The PsyCap subscales showed a significant $\mathrm{R}$ (see Table 3 , as expected), $F(4,116)=24.28, p<.001$. Similar to PsyCap as a whole, the $\mathrm{R}^{2}$ was .46 . The adjusted $\mathrm{R}^{2}$ value was .44 , indicating that $44 \%$ of the variance of wellbeing was accounted for by the sub-scales- that is essentially no difference whether the total score alone or the regression summed four subscale score was used. However, while all four subscales contributed to the overall model it was self-efficacy and optimism that were the significant predictors of PWB, with optimism showing strongest relationship. Our hypothesis was about the total PsyCap score and no hypothesis had been raised about the subscale scores in relation to PWB.

Table 2. Multiple regression showing total psychological capital predicting wellbeing

\begin{tabular}{lccccccc}
\hline Predictor & $\Delta R^{2}$ & $R^{2}$ adj. & $F$ & $B$ & $S E B$ & $\beta$ & $t$ \\
\hline Wellbeing & .44 & .43 & $92.56^{* * *}$ & 70.99 & 15.72 & & $4.51^{* * *}$ \\
PCQ total & & & & 1.18 & .12 & .66 & $9.62^{* * *}$ \\
\hline
\end{tabular}

Note. $N=121 . * \mathrm{p}<0.05 ; * * \mathrm{p}<0.01 ; * * * \mathrm{p}<0.001$.

Table 3. Multiple regression showing the four factors of psychological capital predicting wellbeing

\begin{tabular}{lccccccc}
\hline Predictor & $\Delta R^{2}$ & $R^{2}$ adj. & $F$ & $B$ & $S E B$ & $\beta$ & $t$ \\
\hline Wellbeing & .46 & .44 & $24.28^{* * *}$ & 71.92 & 16.91 & & $4.25^{* * *}$ \\
Self-Eff & & & & 1.19 & .44 & .25 & $2.72^{* * * *}$ \\
Hope & & & & .75 & .53 & .14 & 1.43 \\
Resilience & & & & .70 & .56 & .10 & 1.25 \\
Optimism & & & & 2.10 & .49 & .36 & $4.29^{* * *}$ \\
\hline
\end{tabular}

Note. $N=121 . * \mathrm{p}<0.05 ; * * \mathrm{p}<0.01 ; * * * \mathrm{p}<0.001$.

Hypothesis 2, that Core Self-Evaluations would have a positive relationship with wellbeing, was supported; $R$ was significant, $F(1,119)=154.68, p<.001$, with $R^{2}$ (effect size) at .57 , with an adjusted $R^{2}$ value of .56 indicating that $56 \%$ of the variance in predicting wellbeing was accounted for by total CSE. Furthermore, the subscales of CSE (see Table 4) showed a significant $R, F(1,116)=44.79, p<.001$. Similarly, to the total CSE, the subscales $R^{2}$ was .61, with an adjusted $R^{2}$ value of .59 , indicating that $59 \%$ of the variance in wellbeing was accounted for by the subscales. However, while all four subscales contributed to the overall model it was 
General Self-Efficacy and Self-Esteem that were the most significant predictors of PWB, with general self-efficacy showing strongest relationship. Our hypothesis was about the total CSE score and no hypothesis had been raised about the subscale scores in relation to PWB.

Table 4. Multiple regression for core self-evaluation facets predicting wellbeing

\begin{tabular}{lllllll}
\hline Predictor & $\Delta R^{2}$ & $R^{2}$ adj & $F$ & $B$ & $S E B$ & $\beta$ \\
\hline Constant & .61 & .59 & $44.79^{* * *}$ & 59.69 & 13.61 & \\
Neuroticism & & & 1.59 & .76 & $.19^{*}$ \\
Gen.Self-E. & & & 5.79 & 1.05 & $.43^{* * *}$ \\
Self-esteem & & & 1.80 & .66 & $.23^{* *}$ \\
Locus of C. & & & .90 & .80 & .09
\end{tabular}

Note. $N=121 . * \mathrm{p}<0.05 ; * * \mathrm{p}<0.01 ; * * * \mathrm{p}<0.001$.

Hypothesis 3, that PsyCap and CSE would both contribute positively to wellbeing, was supported (Table 5). When psychological capital is entered at step 1 as a predictor the previous information on the relationship between PsyCap and PWB (0.66) is shown; when CSE is entered at step 2, acting as a mediator, an increase in prediction of PWB occurs (an increase in adjusted $R^{2}$ from 0.43 to 0.66, but with both PsyCap and CSE contributing highly significantly to psychological wellbeing. As can be seen in Table 5, core self-evaluations contribute more highly than PsyCap (0.56 to 0.38 ) but both are needed to predict most successfully high levels of wellbeing (0.66).

Table 5. Hierarchical multiple regression predicting wellbeing from psychological capital and core self-evaluations

\begin{tabular}{llllll}
\hline Predictor & $\Delta R^{2}$ & $R^{2}$ adj & $\beta$ & $B$ & $S E B$ \\
\hline Step 1 & .44 & .43 & & & \\
$\quad$ Constant & & & & 70.99 & 15.72 \\
$\quad$ Psychological Capital & & $.66^{* * * *}$ & 1.18 & .12 \\
Step 2 & .23 & .66 & & & \\
$\quad$ Constant & & & 38.13 & 12.63 \\
Psychological Capital & & & $.38^{* * * *}$ & .67 & .11 \\
$\quad$ Core Self-evaluations & & & $.56^{* * *}$ & 1.60 & .18 \\
\hline
\end{tabular}

Note. $* \mathrm{p}<.05, * * \mathrm{p}<.01, * * * \mathrm{p}<.001$.

Hypothesis 4, that CSE would be a mediator of the PsyCap - Wellbeing relationship, has already been addressed in part (above) in answering hypothesis 3, being supported. However, to test further the hypothesis that total CSE would mediate between PsyCap and wellbeing, the four steps approach was used (Baron \& Kenny, 1986). Step 1: the direct relationship between PsyCap (predictor) with wellbeing (outcome variable) was calculated; Step 2: the predictive relationship between PsyCap and CSE (mediator) was calculated; Step 3: the predictive relationship between CSE (mediator) and the outcome variable (wellbeing) was calculated; and Step 4: both PsyCap and CSE were entered as the predictors of wellbeing in a multiple regression, with results indicating partial mediation had occurred as described next. The total variance explained by the model as a whole was $66 \%$, $F(2,118)=119.41, p<.001$. CSE explained an additional $23 \%$ of the variance in wellbeing, after controlling for PsyCap, $\Delta R^{2}=.23, \Delta F(1,118)=82.70, p<.001$. The bootstrapping method was used. As this process is robust (Preacher \& Hayes, 2008), the Sobel test was not required, and the results showed both PsyCap and CSE contributed significantly to wellbeing.

\section{Discussion}

The aim of this study was to examine the relationships between psychological capital and core self-evaluations in a general sample of Australian workers, and to assess the contribution those psychological resources made to employee wellbeing. People spend much of their adult lives in the workforce, and psychological wellbeing affects all aspects of peoples' lives: health, happiness, job satisfaction, personal performance and relationships. Developing the positive attributes of personality and PsyCap in employees could support wellbeing and foster constructive emotions and behaviour (Žižek et al., 2015) and our study set out to confirm the relationships 
between PsyCap and CSE, and wellbeing.

As expected, Hypothesis 1, that PsyCap would be positively correlated with wellbeing was supported. From the sub-scales, optimism and self-efficacy reached strong significance levels in predicting wellbeing and contributed more than did hope and resilience in this context. This finding mirrored the findings of PsyCap overall in predicting performance (Avey et al., 2010; Stajkovic, 2016) and is consistent with the Culbertson et al. (2010) study linking PsyCap and wellbeing attributes. Self-efficacy has been recognised consistently in many studies as associated with performance and wellbeing (e.g., Hicks \& Knies, 2013; Luthans \& Youssef-Morgan, 2017) as has optimism though to a lesser extent, though the value of PsyCap overall has been demonstrated consistently as indicated.

Hypothesis 2, that CSE would be positively correlated with wellbeing, was also supported. Core Self Evaluations have been, like PsyCap, extensively studied though the scale may not be as well known as the PsyCap scale now is. The four scales that make up the Core Self Evaluations, as were the scales in the PsyCap measure, have been well-investigated and perform in combination in a strongly positive manner (as indicated in Method above, and in research by Chang et al., 2012, Judge \& Hurst, 2007, among others). Our project showed that CSE was strongly predictive of wellbeing, similarly to PsyCap. Our results again mirror earlier results but in different contexts where the trait-like (personality-like) overall CSE scores were related to performance at work (Judge et al., 2003); investigation revealed that general self-efficacy and self-esteem had strong relationships to wellbeing along with neuroticism (negatively).

Hypothesis 3 that PsyCap and CSE would both be positively related to wellbeing was also supported, demonstrating the interplay between states and traits.

Lastly, Hypothesis 4 was supported. CSE partially mediated the relationship between PsyCap and wellbeing.

These findings provide insights to employers, that could facilitate training and development programs that foster PsyCap, CSE and PWB. Previous studies have shown how Psychological Capital Interventions (PCI; Russo \& Stoykova, 2015), were effective when used in a training intervention group and compared to the non-intervention group. The current results further support this training contribution, supporting Locke's Goal-setting theory (1968). For details on Psychological Capital Intervention, see Russo and Stoykova (2015). Bandura's Social Cognitive Theory (1997) was also represented in the study outcomes, demonstrating the ability to regulate behaviour from having developed internal resources, as optimism and hope support emotional regulation. Furthermore, those who are self-efficacious and have increased levels of self-esteem, have a better chance of ensuring success than someone who has lower levels of these resources (Stajkovic, 2006).

\subsection{Contributions to Practice}

In addition to recommending psychological interventions, beneficial contributions might be made in other selfand other- development areas of: life-coaching, therapy, mentoring, leadership and personal development. People who develop personally, become more efficient and engaged at work (Žižek et al., 2015). Previous studies investigating employee wellbeing have explored European and Indian samples (Žižek et al., 2015). The results from this current study can be seen to be useful for Australian organisations in the development of employee training programs targeting this psychological skill-set.

\subsection{Possible Limitations and Sampling Issues, and Future Research and Practice}

A limitation to this study may have been the use of the web-based survey which limited the range of respondents to those who had internet access and technical computer skills. Further, males were somewhat underrepresented, making up just under $40 \%$ of the sample. Ethnicities were not explored. Given that Australia is a multicultural country, caution needs to be taken in viewing the results as generally applicable. Future research might compare groups from different industries and business, and the wellbeing of those in permanent employment positions versus the less stable, temporary - contractual or 'casual' positions, and the effects on wellbeing might also be examined. Suggestions for future research would be to recruit participants that fit specific groups; for example, upper management in organisations, those in stable permanent employment versus those in temporary employment; and those who directly face customers versus office workers who have less/or no interaction. Finally, self-selection bias may have occurred, as individuals volunteered to participate in the online survey. Caution is therefore warranted when interpreting results. Both scales yielded good reliability and were short scales: the CSE was a 12-item scale, whereas the PCQ PsyCap was a 24-item scale. Research has merited the validity of shorter scales (Judge et al., 2003) and industry would support this: however, it is recommended that future studies explore scales of similar length, and perhaps lengthier versions of other relevant variables. 


\subsection{Summary and Implications}

Organisations, consultants and HR personnel should find the short PsyCap and CSE scales helpful in resource assessment and planning in organisations. Functions pertaining to recruitment, selection, training and development can be improved. This study filled a gap in the literature by examining the joint contributions of PsyCap and CSE to PWB, using an employee-based and not a student-based sample. PsyCap and CSE are valuable resources that when cultivated allow individuals the ability to withstand difficult times and exercise better control over events. The findings have demonstrated that Core Self-evaluations and Psychological capital qualities are both important predictors of wellbeing. There is limited research on the sub-facets of PsyCap and CSE but it would seem from our study that optimism (in PsyCap) and General Self-Efficacy (in CSE) could be given special attention in developing wellbeing outcomes.

Recommendations for future research include to continue the exploration with different populations; recommendations for practice in organisations include implementing programs that will foster improved PsyCap and CSE qualities. Organisations that invest in the development and management of employee PsyCap, CSE (and wellbeing), will ensure advantage in the business world by growing teams of committed, efficient, confident, and initiative exploring employees. Fostering PsyCap is beneficial for all business organisations, with likely contribution to lower turnover, less sickness and deviant behaviour, and better performance in the workplace (e.g., Diener \& Seligman, 2004).

In conclusion, wellbeing affects all human functioning: health, relationships, life satisfaction, and personal performance. The findings from the current paper show that Psychological Capital and Core Self-Evaluations attributes are associated directly with psychological wellbeing. Further studies are needed but organisational managers can use the results to plan successful growth of their human resource capabilities via development of appropriate tailored interventions that broaden and build PsyCap and core self evaluations in their employees.

\section{References}

Avey, J.B., Luthans, F., Smith, R.M., \& Palmer, N.F. (2010). Impact of positive psychological capital on employee well-being over time. Journal of Occupational Health Psychology, 15, 17. https://doi.org/10.1037/a0016998

Avey, J. B., Luthans, F., \& Jensen, S. M. (2009). Psychological capital: A positive resource for combating employee stress and turnover. Human Resource Management, 48(5), 677-693. https://doi.org/10.1002/hrm.20294

Bandura, A. (1997). Self-efficacy: The exercise of control. New York: W.H. Freeman.

Baron, R. M., \& Kenny, D. A. (1986). The moderator-mediator variable distinction in social psychological research: Conceptual, strategic, and statistical considerations. Journal of Personality and Social Psychology, 51, 1173-1182. https://doi.org/10.1037/0022-3514.51.6.1173

Chang, C., Ferris, D., Johnson, R., Rosen, C., \& Tan, J. (2012). Core self-evaluations: A review and evaluation of the literature. Journal of Management, 38(1), 81-128. https://doi.org/10.1177/0149206311419661

Coutu, D. L. (2002). How resilience works. Harvard Business Review, 80(5), 46.

Culbertson, S. S., Fullagar, C. J., \& Mills, M. J. (2010). Feeling good and doing great: The relationship between psychological capital and wellbeing. Journal of Occupational Health Psychology, 15, 421-433. https://doi.org/10.1037/a0020720

Diener, E., \& Seligman, M. E. P. (2004). Beyond money: Toward an economy of wellbeing. Psychological Science in the Public Interest: A Journal of the American Psychological Society, 5, 1. https://doi.org/10.1111/j.0963-7214.2004.00501001.x

Dormann, C., Fay, D., Zapf, D., \& Frese, M. (2006). A state-trait analysis of job satisfaction: on the effect of core self-evaluations. Applied Psychology, 55, 27-51. https://doi.org/10.1111/j.1464-0597.2006.00227.x

Graham, L. (2013). Bouncing back: Rewiring your brain for maximum resilience and wellbeing. Novato, California: New World Library.

Judge, T.A. (2009). Core self evaluations and work success. Current Directions in Psychological Science, 18(1), 58-62. https://doi.org/10.1111/j.1467-8721.2009.01606.x

Judge, T. A., \& Bono, J. E. (2001). Relationship of core self-evaluations traits-self-esteem, generalized self-efficacy, locus of control, and emotional stability-with job satisfaction and job performance: A meta-analysis. Journal of Applied Psychology, 86(1), 80. https://doi.org/10.1037//0021-9010.86.1.80

Judge, T. A., Erez, A., Bono, J. E., \& Thoresen, C. J. (2003). The core self-evaluations scale: Development of a 
measure. Personnel Psychology, 56, 303-331. https://doi.org/10.1111/j.1744-6570.2003.tb00152.x

Judge, T.A., \& Hurst, C. (2007a). Capitalizing on one's advantages: Role of core self-evaluations. Journal of Applied Psychology, 92, 1212- 1227. https://doi.org/10.1037/0021-9010.92.5.1212

Karatepe, O. M., \& Karadas, G. (2015). Do psychological capital and work engagement foster frontline employees' satisfaction? A study in the hotel industry. International Journal of Contemporary Hospitality Management, 27, 1254-1278. https://doi.org/10.1108/IJCHM-01-2014-0028

Knies, E., \& Hicks, R.E. (2013). Resilience, optimism, hope, and self-efficacy in handling the Global Financial Crisis: Experiences of employees in a multinational industrial organisation operating in Europe, Asia and the United States. In: Proceedings of the 2013 Conference of the Centre of Full Employment and Equity and the 19th Annual National Conference on Unemployment, University of Newcastle, Australia

Levenson, H. (1981). Differentiating among internality, powerful others, and chance. In H.M. Lefcourt (Ed.), Research with the locus of control construct (pp. 15-63). New York: Academic Press. https://doi.org/10.1016/B978-0-12-443201-7.50006-3

Locke, E. A., \& Latham, G. P. (2006). New directions in goal-setting theory. Current Directions in Psychological Science, 15, 265-268. https://doi.org/10.1111/j.1467-8721.2006.00449.x

Locke, E. A., McClear, K., \& Knight, D. (1996). Self-esteem and work. International Review of Industrial and Organizational Psychology, 11, 1-32.

Luthans, F., \& Avolio, B. J. (2014). Brief summary of psychological capital and introduction to the special issue. $\begin{array}{lllll}\text { Journal of Leadership \& Organisational Studies, } & 21(2), & 125-129 .\end{array}$ https://doi.org/10.1177/15480518113518073

Luthans, F., Avolio, B. J., Avey, J. B., \& Norman, S. M. (2007). Positive psychological capital: Measurement and relationship with performance and satisfaction. Personnel Psychology,60, 541-572. https://doi.org/10.1111/j.1744-6570.2007.00083.x

Luthans, F., Luthans, K. W., \& Luthans, B. C. (2004). Positive psychological capital: Beyond human and social capital. Business Horizons, 47, 45-50. https://doi.org/10.1016/j.bushor.2003.11.007

Luthans, F., \& Youssef, C. M. (2007). Emerging positive organizational behavior. Journal of Management, 33, 321-349. https://doi.org/10.1177/0149206307300814

Luthans, F., \& Youssef-Morgan, C. M. (2017). Psychological capital: An evidence-based positive approach. Annual Review of Organisational Psychology and Organisational Behaviour, 4, 339-366. https://doi.org/10.1146/annurev-orgpsych-032516-113324

McCrae, R. R., \& Costa, P. T. (1987). Validation of the five-factor model of personality across instruments and $\begin{array}{lllll}\text { observers. Journal of Personality and } & \text { Social }\end{array}$ https://doi.org/10.1037/0022-3514.52.1.81

Mitchell, J., \& Kristovics, A. (2005). Death of an airline: the well-being of retrenched Ansett staff-three years on. International Journal of Employment Studies, 13(2), 89.

Preacher, K., \& Hayes, A. (2008). Asymptotic and resampling strategies for assessing and comparing indirect effects in multiple mediator models. Behavior Research Methods, 40, 879-891. https://doi.org/10.3758/BRM.40.3.879

Rath, T., \& Harter, J. (2010). The economics of wellbeing. Gallup Press. Retrieved January, 23, 2015.

Rotter, J. B. (1966). Generalized expectancies for internal versus external control of reinforcement. Psychological Monographs: General \& Applied, 80, 1. https://doi.org/10.1037/h0092976

Russo, S., \& Stoykova, P. (2015). Psychological capital intervention (PCI): A replication and extension. Human Resource Development Quarterly, 26, 329-347. https://doi.org/10.1002/hrdq.21212

Ryff, C. D. (1989). Happiness is everything, or is it? explorations on the meaning of psychological wellbeing. Journal of Personality \& Social Psychology, 57, 1069-1081. https://doi.org/10.1037/0022-3514.57.6.1069

Ryff, C. D., \& Keyes, C. L. M. (1995). The structure of psychological wellbeing revisited. Journal of Personality \& Social Psychology, 69, 719-727. https://doi.org/10.1037/0022-3514.69.4.719

Ryff, C. D., \& Singer, B. H. (2013). Know thyself and become what you are: A eudaimonic approach to psychological well-being. In The Exploration of Happiness (pp. 97-116). Springer: Netherlands. 
https://doi.org/10.1007/978-94-007-5702-8_6

Schneider, S. L. (2001). In search of realistic optimism: Meaning, knowledge, and warm fuzziness. American Psychologist, 56, 250. https://doi.org/10.1037/0003-066X.56.3.250

Schulman, P. (1999). Applying learned optimism to increase sales productivity. Journal of Personal Selling \& Sales Management, 19(1), 31-37.

Seligman, M. E. (2002). Positive psychology, positive prevention, and positive therapy. Handbook of Positive Psychology, 2, 3-12. Retrieved from: http://www.positiveculture.org/uploads/7/4/0/7/7407777/seligrman_intro.pdf

Sherer, M., Maddux, J. E., Mercandante, B., Prentice-Dunn, S., Jacobs, B., \& Rogers, R.W. (1982). The self-efficacy scale: Construction and validation. Psychological Reports, 51, 663-671. https://doi.org/10.2466/pr0.1982.51.2.663

Snyder, C. R. (2002). Hope theory: Rainbows in the mind. Psychological Inquiry, 13(4), 249-275. https://doi.org/10.1207/S15327965PLI1304_01

Snyder, C. R., Harris, C., Anderson, J. R., Holleran, S. A., Irving, L. M., Sigmon, S. T., Yoshinobu, L., Gibb, J., Langelle, C., \& Harney, P. (1991). The will and the ways: Development and validation of an individual-differences measure of hope. Journal of Personality \& Social Psychology, 60, 570-585. https://doi.org/10.1037/0022-3514.60.4.570

Sparks, K., Faragher, B., \& Cooper, C. L. (2001). Well-being and occupational health in the 21st century

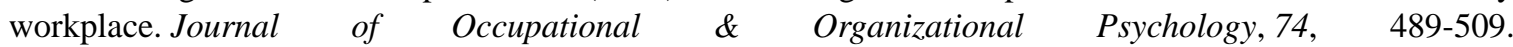
https://doi.org/10.1348/096317901167497

Stajkovic, A. D. (2006). Development of a core confidence-higher order construct. Journal of Applied Psychology, 91, 1208-24. https://doi.org/10.1037/0021-9010.91.6.1208

Sutcliffe, K. M., \& Vogus, T. J. (2003). Organizing for resilience. In Cameron, K., Dutton, J., \& Quinn, R. (Eds) Positive organizational scholarship: Foundations of a new discipline, pp. 94-110. San Francisco: Berrett-Koelher Press.

Tora, I., Martinez, J.M., Benavides, F.G., Leveque, K., \& Ronda, E. (2015). Effect of economic recession on psychosocial working consitions by workers' nationality. International Journal of Occupational \& Environmental Health, 21(4), 328-332. https://doi.org/10.1080/10773525.2015.1122369

Tsaousis, I., Nikolaou, I., Serdaris, N., \& Judge, T. A. (2007). Do the core self-evaluations moderate the relationship between subjective well-being and physical and psychological health? Personality and Individual Differences, 42, 1441-1452. https://doi.org/10.1016/j.paid.2006.10.025

Watson, D. C. (2001). Procrastination and the five-factor model: A facet level analysis. Personality and Individual Differences, 30, 149-158. https://doi.org/10.1016/S0191-8869(00)00019-2

Yang, H. C., \& Cho, H. Y. (2015). Small and medium business workers' positive psychological capital, life satisfaction, and innovative work behavior. Journal of Distribution Science, 13(7), 25-31. https://doi.org/10.15722/jds.13.6.201507.25

Žižek, S., Treven, S., \& Čančer, V. (2015). Employees in Slovenia and their psychological wellbeing based on Ryff's model of psychological wellbeing. Social Indicators Research, 121, 483-502. https://doi.org/10.1007/s11205-014-0645-3

\section{Copyrights}

Copyright for this article is retained by the author(s), with first publication rights granted to the journal.

This is an open-access article distributed under the terms and conditions of the Creative Commons Attribution license (http://creativecommons.org/licenses/by/4.0/). 